\title{
UIO Editorial
}
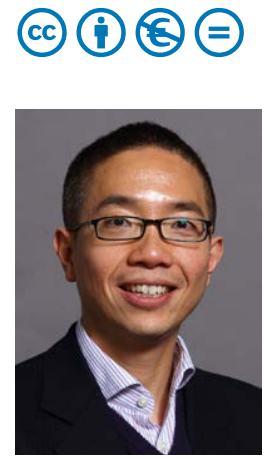

Adrian Lim
Bibliography

DOI https://doi.org/10.1055/a-0731-6059

Ultrasound Int Open 2018; 4: E109

(c) Georg Thieme Verlag KG Stuttgart · New York

ISSN 2199-7152

Correspondence

Adrian Lim, MD

Charing Cross Hospital

Imperial College

London

United Kingdom

Tel.: +02088461854

a.lim@imperial.ac.uk
It is with great pleasure again that I introduce the December 2018 issue of Ultrasound International Open.

This issue has a focus on Neck ultrasound where the first article highlights the value of careful sonographic observations of thyroid nodules which will improve diagnostic accuracy and help select suspicious nodules for histological sampling. The article also provides many examples and highlights some helpful tips.

The third and fourth articles discuss unusual findings of neck lumps and provides a differential and pictorial review of uncommon diagnoses to consider.

On a theme of high frequency ultrasound, there is a case report of an unusual inguinal hernia content and a myofibrosarcoma of the chest wall mimicking vascular thrombosis. There is also an article on ultrasonic diagnosis of the rare Rubinstein-Taybi syndrome.
Finally, a couple of articles describe how to get the most out of ultrasound in routine daily clinical work, namely estimating the size of a pleural effusion and where it is most accurate to measure and an innovative renal Doppler index in aiding the diagnosis of cardiorenal syndrome.

Overall, there is something for everybody. We hope you enjoy the selection.

On behalf of the UIO editors.

Adrian Lim 